\title{
Brain involvement in the use of games in nursing education
}

\author{
Sadaf S. Murad * \\ Faculty of Nursing, University of Alberta, Edmonton, Alberta, Canada
}

Received: September 21, 2015

DOI: $10.5430 /$ jnep.v7n6p90
Accepted: January 13, 2017

Online Published: January 20, 2017

\begin{abstract}
In this high-speed world in which everything is technologically driven, higher education also needs to incorporate technology into the scope of teaching pedagogy. Aligning educational games with the nursing curriculum is one way to address the need for technologically knowledgeable learners. Learning occurs in gaming environment is experimental, and constructive. Albeit, threading them in the nursing curriculum required in-depth knowledge about understanding brain involvement in this process. Nurse educators can thread gaming into the nursing content to ensure that learning occurs in a friendly environment. Learning games stimulates the release of dopamine in the midbrain, and the learning becomes part of long-term memory. The games must challenge and augment students' interest so they get involved in the learning journey. The challenging environment, with clearly listed goals and ongoing feedback enhances learners' interest and learning become part of their long-term memory. Gaming is an incomparable way of helping nursing students to learn actively and master learning skills. This literature review will discuss the phenomenon of gaming in education, the parts of brain that involved in educational games, scaffolding teaching and learning theories in designing educational games to improve and at last highlight the significance of gaming in nursing pedagogy. Use of games will open new horizon of possibilities to address various learning of different kinds of learners. This paper will act as a foundation to better comprehend the effective use of virtual world in academia.
\end{abstract}

Key Words: Nursing pedagogy, Virtual world, Quest based, Gaming, Innovative strategy, Technological driven learners

\section{INTRODUCTION}

In this high-speed world, where everything is technologically driven, it is crucial that higher education incorporates the use of technology into teaching pedagogy. The latest generations are technologically savvy, and their innovative minds require interactive teaching styles to inspire motivation, critical thinking, and self-confidence. Integrating educational games into the curriculum is a way to address the needs of these technologically knowledgeable learners. Games have been used in education for a century, but their use in nursing education is still in its infancy. Nursing education has relied on didactic methods of teaching, which create a more passive learning environment, ${ }^{[1]}$ and nursing faculties often face challenges in nurturing leadership and decision making skills in nurses. Nursing profession significantly struggled in past as being passive or skill oriented profession. Nursing is the mixture of art and science, and for better caring nurse we need innovative, active learners and critical thinkers. Game-based learning is a creative platform that allows nursing instructors to use technology and gaming in appropriate way to enhance interest of students in nursing education. Game based environment also beneficial for faculty member to incorporate different teaching styles to address the diverse needs of learners. Use of educational games in teaching process will not only expand knowledge and skills of nursing students but also fine-tuned their brain health. Pur-

*Correspondence: Sadaf S. Murad; Email: smurad@ualberta.ca; Address: Faculty of Nursing, University of Alberta, Edmonton, Alberta, Canada. 
pose of this systematic review is to understand response of brain in game-based learning environment and how to use a game-based approach properly in academia to spark learning in the age of technology.

\section{METHOD}

A review of the research literature was conducted to identify key published evidence discussing process of brain involvement in gaming process and how it can be well integrated in the process of teaching and learning. With the assistance of a health science librarian, search strategies were developed to maximize retrieval of evidence published on the topic. Electronic databases reviewed included: CINAHL, PubMed, Medline (Ovid), ProQuest Dissertations \& theses Full-text, EMBASE (Ovid), Cochrane Database of Systematic Reviews (Ovid EBM Reviews), and Abstracts on gaming and nursing education. The key words searched separately, and in various combinations included nursing education and gaming, use of game and brain involvement, brain and gaming, gaming and student success, brain response in gaming environment, and significance of gaming in education. Reference lists of retrieved articles were examined for additional research articles, book chapters, and gray literature that examined the phenomenon of brain involvement in the use of game in nursing education.

A total of 54 research articles published in peer-reviewed journals between 2000 and 2016 that addressed the phenomena of use of brain, gaming and nursing education were reviewed. Studies were included if they met the following criteria: a) studies conducted on use of gaming in education, b) describe the process of brain involvement in game based learning environment, c) address the significance of gaming in nursing education, d) describe various of ways of hooking game-based learning environment within the paradigm of nursing education, e) empirical studies, and f) articles written in English.

Out of 54 studies, 11 selected for the review. The main themes emerge in these articles are: understanding the use of games in education, understanding brain parts which need to be thread in correctly to amplify the students learning, use of teaching learning theories in designing games for learning purpose and significances of it in nursing curriculum. To ensure the credibility of the retrieved articles, only research studies that explained the selection criteria and described the research approach were included.

\section{Gamification and education}

Game is type of experiential learning with precise set of rules in which player utilize knowledge and skill to achieve certain goals. ${ }^{[2]}$ Gaming allows learners to be an active partic- ipant in the process of knowledge translation and get mastery over new knowledge in friendly environment. It focuses on student learning rather than on grades. Student can make trial and error until they retain the information completely. Learning which occur in non-punitive environment is more productive and retaining as compare to highly competitive environment. Use of game in education helps learners to integrate theory into practice. ${ }^{[2]}$ It also allows integrating various learning styles to address the needs of different types of learners.

\section{HOOKING THE PARTS OF BRAIN IN GAM- ING WORLD}

Neuroscience is the branch of science that helps to understand the roles of cognition, emotion, and motivation in a virtual learning environment. Reward and motivation in terms of neuroscience result in certain behaviors required to achieve a goal or a meaningful outcome. ${ }^{[3]}$ Another important aspect that need to be understood is the integration of associative memory for successful long-term learning outcome.

\subsection{Effect of dopamine on the reward system}

Dopamine in the midbrain region plays a dominant role in reward and motivation. ${ }^{[4]}$ Research on dopamine receptors has shown that humans' receipt of a reward results in a burst of activity in the brain known as the phasic phase. ${ }^{[3]}$ For example, in a gaming lab when learners receive rewards for tasks such as extra points or badges, dopamine activity in the midbrain increases, and dopamine released. Learners become motivated and engaged in the tasks that they are performing, which becomes part of their memory. However, if rewards are expected based on prior experience, then the neurons respond to the predictive clue rather than to the reward. ${ }^{[3]}$ In other words, when learners know that they will receive a reward after they complete a challenging task, based on their prior experience of having received a reward, the brain automatically releases dopamine before they complete the task. Thus, the phasic response of the neurons differs between an unexpected and an expected reward, which is known as prediction error. ${ }^{[4]}$ Perhaps more interesting is that the element of uncertainty or challenge increases the dopaminergic activity, and learners become deeply immersed in the learning process.

\section{Dopamine and the modulation of long-term memory}

The midbrain dopamine neurons have a direct impact on the hippocampus, which regulates long-term memory. Research has revealed that the action of dopamine on the hippocampal synapses is necessary to enhance and maintain learned behavior in long-term memory. ${ }^{[3]}$ However, to enhance the activity 
of dopamine, the virtual environment must be challenging, have certain outcomes, and result in continuous feedback. If learning is challenging, based on the trial-and-error approach, immediate feedback, and the inclusion of rewards, the outcome of that learning is sustainable for a long time, and it will become part of long-term memory. Thus, feedback has a positive influence on the transformation of episodic memory and knowledge into long-term memory.

\subsection{Associative memory}

Associative memory is the part of neural network, which helps in making learning part of long-term memory. ${ }^{[5]}$ Prefrontal and hippocampus in human brain are responsible for memory consolidation. Learning that stimulates prefrontal and hippocampus will become part of long-term memory. Use of strategies such as Audio-visual aid in gaming lab, and creating avatars are productive way to integrate it in the gaming environment for productive learning. Audio-visual material in the game stimulate associative memory and become unforgettable learning for learners. ${ }^{[6]}$ For example; on scene of massive trauma visual stimulus of ambulance, triaging causalities and healthcare roles in handling trauma will be the visual stimulus and audio sound of ambulance, victims cry for help and healthcare team members' conversation will be the auditory stimulus. Embedding learning scenario with AV effects and avatars will left unforgettable learning image in learners' mind. This will stimulate neural networks and the content will retain in the associative memory of learners' brain.

Audio-visual scenes catalyst the learning process and learning will be processed towards the long-term memory. ${ }^{[7]}$ Another major advantage is that learners easily dwell into different kinds of learning experience without being in danger. Exposing learners with different kinds of emergency situations in real patients is difficult at times, however, with help of gaming this can be possible. It also helps nursing students to be well prepared for practical world. In sum, if learning becomes part of associative memory, learners can easily retrieve the gained knowledge whenever they want and act promptly.

\section{TEACHING LEARNING THEORY IN GAMES}

In this technology-driven world in which information is available with the click of a mouse, it is challenging to decide what to use to engage learners in the learning process. The Horizon report in the United States ${ }^{[8]}$ cautioned that games that are to be used as pedagogical platforms in higher education must be designed carefully because not only are they a medium of entrainment, but they also scaffold higher-order thinking, decision making, practical skills, and team-leading skills and help learners to develop their expertise. Games need to be designed to allow time for debriefing, to increase students, and facilitators' connectedness, to focus on continuous student growth with valuable ongoing feedback, and to create an active learning process. ${ }^{[9]}$ Therefore, game design need to be based on teaching learning theory to maximize the learning process. ${ }^{[10]}$ Two well-known theories that can implement successfully in gaming world to enhance the learning journey are self-determination theory and social cognitive theory.

\subsection{Self determination theory}

It is a theory of human motivation that focus on intrinsic and extrinsic factors to enhance individuals' motivation for successful outcome. Intrinsic motivation defined as persuasiveness to achieve something regardless of external outcomes. ${ }^{[11]}$ Extrinsic outcome defined as external rewards, positive feedback, and other achievable outcome to enhance learners' interest in educational games. Learning occurs in gaming context provide rich medium to motivate learners intrinsic and extrinsic drive to achieve excellence. Game designed for educational purpose need to incorporate use of social determination theory via using different badges, rewards, proper direction for different games levels and achievements and timely feedback in order to immerse learners mind in learning experience.

\subsection{Social cognitive theory}

Another theory that need to be hook to design educational games is social cognitive theory. Social cognitive theory explains the process of behavior change. To bring effectual change, personal and environmental factors play a major role. This theory highlights the importance of self-determination and timely feedback. ${ }^{[12]}$ In gaming, learners' personal motivation, self-efficacy, and interest sandwich with timely feedback, direction and guidance by instructor for successful outcome in the form of long-term retention of knowledge and skills.

The use of learning theories as a framework in designing educational games is deem necessary for productive outcome.

\section{THE SIGNIFICANCE OF GAME-BASED LEARNING IN NURSING EDUCATION}

Stress or the fear of making mistakes in the presence of classmates impedes student learning; however, a gaming environment decreases that fear. Students' brains become fully engaged in a gaming environment, which increases their motivation and encourages them to become deeply submersed in the learning process. Gaming fosters critical thinking, decision-making skills in students and prepares them to be- 
come a better nurse in practical settings. The fear of grading on assignments and bell-curve marking increase learners' fear, but using gaming strategies helps learners to incorporate feedback to achieve the desired outcome and decreases their anxiety over low grades. In nursing education students are becoming more tasks oriented and competitive, which impacts their professional outcomes as nurses. ${ }^{[1]}$ However, the use of gaming technology in higher education is an effective solution to these issues because it helps learners to improve and gives them all an equal opportunity to improve their assignments to achieve good grades. This shifts the grading from a bell curve to a mastery approach to learning. Bloom (1982) defined mastery learning as an approach in which students receive a detailed description of the content and enough time to complete the activities. ${ }^{[13]}$ The faculty members give them formative feedback on their work and sufficient time to look over their work to master the concepts or skills. This technique in a virtual environment helps nursing students with different learning styles to use activities that work best for them and helps them to master the learned concepts. ${ }^{[14]}$

Another positive aspect of a game-based approach to nursing education is humor, which is a most effective tool in the teaching and learning process to decrease learners' anxiety and makes them joint partners in their learning. Humor increases the release the dopamine in the bloodstream and enhances the attention span of learners. However, the correct use of humor in the gaming world can be critical. ${ }^{[4]}$ Skinner (2001) stipulated that humor must have a pedagogical purpose; otherwise, it is not relevant to learning even if the students laugh and enjoy themselves. In other words, "humor should be neither gratuitous nor excessive, but judicious" (p. 53). ${ }^{[15]}$ Humor must fit well with the curriculum content in a gaming environment, because facilitators do not have enough opportunity in a virtual environment to clarify the meaning embedded in fun-filled activities. This can create hurdles for learners and cause them to lose interest in performing their tasks. Watching YouTube videos, singing songs, participating in role-play based on clinical scenarios, and playing word trivia games in a virtual world are examples of how to use humor with a gaming technique. ${ }^{[9]}$
New learning or new challenging environment stimulate the brain as part of the survival process. ${ }^{[4]}$ When new learning occurs in a challenging environment, the information moves into the midbrain, and in a supportive and friendly environment, learners easily adjust to new and innovative learning methods. When learners are introduced to new stimuli in the form of challenging games, their dopamine level increases, and learning occurs in the frontal brain. ${ }^{[4]}$ Therefore, games must be challenging, and learners must be engaged in gamebased learning. If the task is too easy or too complicated, learners lose interest; therefore, their teachers must be careful while creating virtual games or quests. When learners' curiosity about different levels of a game is piqued or they receive different rewards or badges in a virtual environment, their sense of novelty enhanced, and they become excited to learn new concepts. Curiosity in nursing education is essential to lifelong learning, and nurse educators have a great responsibility to promote it in academic and clinical settings. ${ }^{[16]}$

\section{Conclusion}

In this revolutionary world in which everything changes in the blink of an eye, teaching and learning strategies also need to be innovative to engage learners, and help them to develop professional skills. The use of gaming is not a new phenomenon in nursing education, but still in its infancy because of unfamiliarity of its appropriate use in academia. Faculty members should have basic knowledge of brain parts, which need to be, integrate appropriately for better outcome. Use of teaching learning theories as framework is another significant factor for effective learning outcome in gaming technique. Games need to fit well into the nursing curriculum to retain learners' interest, enhance their self-confidence, leadership skills, and prepare them to integrate theory into practice in the clinical settings. Gaming techniques help nursing instructors to accommodate different types of learning styles to address students' diverse learning needs. Appropriate use of gaming pedagogy in nursing curriculum will result in well-prepared nurse with admirable knowledge and skills.

\section{CONFLicts OF INTEREST Disclosure}

The author declares that there is no conflict of interest.

\section{REFERENCES}

[1] Boctor L. Active-learning strategies: The use of a game to reinforce learning in nursing education: A case study. Nurse Education in Practice. 2013; 13(2): 96-100. PMid:22910398 https: //doi.org/10.1016/j.nepr.2012.07.010

[2] Strickland HP, Kaylor SK. Bringing your a-game: Educational gam- ing for student success. Nurse Education Today. 2016; 40: 101-103. PMid:27125157 https://doi.org/10.1016/j.nedt.2016.02 .014

[3] Shohamy D, Adcock RA. Dopamine and adaptive memory. Trends in Cognitive Sciences. 2010; 14(10): 464-472. PMid:20829095 https://doi.org/10.1016/j.tics.2010.08.002 
[4] Howard-Jones PA. Minds, brains and learning games. In Acer research conference 2013: How the brain learns: What lessons are there for teaching? 2013. 16-23 P. Available from: http://research.acer.edu.au/cgi/viewcontent.c gi?article=1163\&context=research_conference

[5] Sommer FT. Associative Memory and Learning. In Encyclopedia of the Sciences of Learning (pp. 340-342). Springer US. 2012.

[6] Yu X, Li Z, Zhou C, et al. A Design Proposal of Game-Based Professional Training System for Highly Dangerous Professions. College of Computer and Software in Taiyuan University of Technology. 2009.

[7] Ferguson C, Davidson PM, Scott PJ, et al. Augmented reality, virtual reality and gaming: an integral part of nursing. Contemporary Nurse. 2015; 51(1): 1-4. PMid:26678947 https://doi.org/10.1080/ 10376178.2015.1130360

[8] Johnson L, Levine A, Smith R, et al. The 2010 Horizon report. Austin, TX: New Media Consortium. 2010.

[9] Baid H, Lambert N. Enjoyable learning: The role of humour, games, and fun activities in nursing and midwifery education. Nurse Education Today. 2010; 30(6): 548-552. PMid:20044181 https: //doi.org/10.1016/j.nedt.2009.11.007

[10] Giunti G, Baum A, Giunta D, et al. Serious Games: a concise overview on what they are and their potential applications to health- care. In MEDINFO 2015: EHealth-enabled Health: Proceedings of the 15th World Congress on Health and Biomedical Informatics. IOS Press. 2015. PMid:26262077

[11] Ryan RM, Deci EL. Self-determination theory and the facilitation of intrinsic motivation, social development, and well-being. American Psychologist. 2000; 55(1): 68. PMid:11392867 https : //doi.org/10.1037/0003-066X.55.1.68

[12] Bandura A. Social foundations of thought and action: A social cognitive theory. Prentice-Hall, Inc. 1986.

[13] Bloom BS. All our children learning. A primer for parents, teachers, and other educators. New York, NY: McGraw-Hill. 1982.

[14] Hunter WJ. Use your head: Neuroscience research and teaching. College Quarterly. 2011; 14(3): 8.

[15] Skinner NF. A course, a course, my kingdom for a course: Reflections of an unrepentant teacher. Canadian Psychology. 2001; 42(1): 49-60. https : //doi.org/10.1037/h0086879

[16] Kedge S, Appleby B. Promoting a culture of curiosity within nursing practice. British Journal of Nursing. 2009; 18(10): 635 637. PMid:19491739 https ://doi.org/10.12968/bjon. 2009 .18 .10 .42485 